\title{
INFLUENCE OF THE MISDEF ALGORITHM ON THE THERAPEUTIC DECISION FOR VERTEBRAL DEFORMITY IN THE ADULT
}

\author{
INFLUÊNCIA DO ALGORITMO MISDEF NA DECISÃO TERAPÊUTICA DE DEFORMIDADE \\ VERTEBRAL EM ADULTOS
}

\section{INFLUENCIA DEL ALGORITMO MISDEF EN LA DECISIÓN TERAPÉUTICA DE DEFORMIDAD VERTEBRAL EN ADULTOS}

\author{
Gullherme Zandavalli Ramos, ${ }^{1}$ Emillano Vialle, ${ }^{1}$ Rafael luiz Pinto, ${ }^{1}$ Cristiano Menezes, ${ }^{2,3}$ Maurício Santos Gusmão, ${ }^{4,5}$ Nicolas González Masanés, ${ }^{6}$ \\ asdrubal Falavigna, ${ }^{7}$ Chárbel Jacob Junior, ${ }^{8}$ Luiz Roberto Vialle, ${ }^{1}$ Ramon Ferreira, 7 Guilhermo Holtman ${ }^{9}$
}

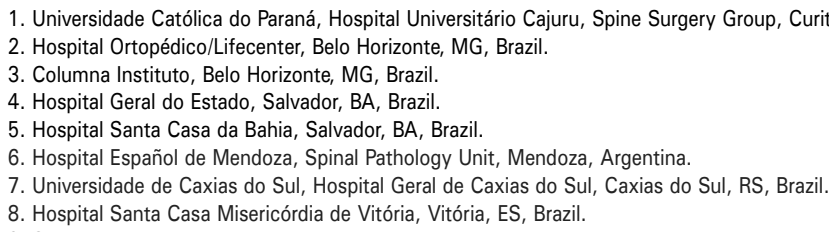

9. Sanatorio Profesor Itoiz, Buenos Aires, Argentina.

\begin{abstract}
Objective: The therapeutic decision in cases of adult spinal deformity takes numerous factors into account with a consequent variability in treatment options. The objective is to compare the impact of the MISDEF (minimally invasive spine deformity) algorithm on therapeutic decisions in cases of adult spinal deformity. Methods: Prospective radiographic analysis of 40 cases of adult deformity. The cases were sent, in two steps, to 20 Latin American surgeons who had to choose among six treatment options with and without the use of the MISDEF. Results: For the conducts of decompression, decompression and short fusion, decompression and fusion with interbody device, and osteotomy with extension of fusion to the thoracic spine, no significant differences were found when comparing decisions made with and without MISDEF. For osteotomy, we observed a tendency for the number of surgeons choosing this conduct to increase when the decision is made with MISDEF. We observed that the number of surgeons who decided on conservative treatment decreased with the use of MISDEF $(p<0.001)$. In cases with sagittal vertical axis $<6 \mathrm{~cm}$ or pelvic tilt $<25^{\circ}$ or $\mathrm{PI}-\mathrm{LL}$ (pelvic incidence minus lumbar lordosis) $<10^{\circ}$ or coronal curve $<20^{\circ}$, there was a decrease in the conservative treatment option and an increase in osteotomy with proximal extension of the fusion with the use of MISDEF. Conclusions: There is a tendency to increase indications of osteotomy and decrease the conservative treatment option when making a decision with MISDEF. The use of the algorithm showed no significant impact on the therapeutic decision in severe cases of adult deformity. Level of Evidence II; Prospective comparative radiographic analysis.
\end{abstract}

Keywords: Adult; Scoliosis; Spine; Conservative Treatment; Osteotomy.

\section{RESUMO}

Objetivo: A decisão terapêutica em casos de deformidade vertebral em adultos considera inúmeros fatores com consequente variabilidade na opção de tratamento. O objetivo consiste em comparar o impacto do algoritmo MISDEF (minimally invasive spine deformity) na decisão terapêutica em casos de deformidade vertebral em adultos. Métodos: Análise radiográfica prospectiva de 40 casos de deformidade em adultos. Os casos foram enviados, em duas etapas, para 20 cirurgiões da América Latina que deveriam escolher entre seis opções de tratamento sem e com a utilização do MISDEF. Resultados: Para as condutas descompressão, descompressão e fusão curta, descompressão e fusão com dispositivo intersomático e osteotomia com extensão para coluna torácica não foram encontradas diferenças significativas quando comparadas às decisões sem e com MISDEF. Para osteotomia, observa-se uma tendência de que o número de cirurgiões que escolhe essa conduta aumenta quando a decisão é feita com MISDEF. Observou-se que o número de cirurgiões que decide por tratamento conservador diminui com a utilização do MISDEF $(p<0,001)$. Em casos com eixo vertical sagital $<6 \mathrm{~cm}$ ou inclinação pélvica $<25^{\circ}$ ou IP-LL (incidência pélvica menos lordose lombar) $<10^{\circ}$ ou curva coronal $<20^{\circ}$, houve diminuição da opção por tratamento conservador e aumento da indicação de osteotomia com extensão proximal da fusão com o uso do MISDEF. Conclusões: Há uma tendência em aumentar as indicações de osteotomia e diminuir a opção por tratamento consenvador na tomada de decisão com MISDEF. A utilização do algoritmo não demonstrou impacto expressivo na decisão terapêutica em casos graves de deformidade em adultos. Nível de evidência II; Análise radiográfica prospectiva comparativa.

Descritores: Adulto; Escoliose; Coluna Vertebral; Tratamento Conservador; Osteotomia.

\section{RESUMEN}

Objetivo: La decisión terapéutica en casos de deformidad en adultos considera innumerables factores, con la consiguiente variabilidad en la opción de tratamiento. El objetivo consiste en comparar el impacto del algoritmo MISDEF (minimally invasive spine deformity) en la decisión terapéutica en casos de deformidad vertebral en adultos. Métodos: Análisis radiográfico prospectivo de 40 casos de deformidad 
del adulto. Los casos fueron enviados, en dos etapas, a 20 cirujanos de América Latina que deberían elegir entre seis opciones de tratamiento sin y con uso del MISDEF. Resultados: Para las conductas descompresión, descompresión y fusión corta, descompresión y fusión con dispositivo intersomático y osteotomía con extensión para columna torácica, no se encontraron diferencias significativas al comparar decisiones sin y con MISDEF. Para osteotomía, se observa una tendencia de que el número de cirujanos que elige esta conducta aumenta cuando la decisión es hecha con MISDEF. Se observó que el número de cirujanos que decide por tratamiento conservador disminuye con el uso del MISDEF ( $p<0,001)$. En casos con eje vertical sagital $<6 \mathrm{~cm}$ o inclinación pélvica $<25^{\circ}$ o IP-LL (incidencia pélvica menos lordosis lumbar) $<10^{\circ}$ o curva coronal $<20^{\circ}$, hubo disminución de la opción por tratamiento consenvador y aumento de la indicación de osteotomía con extensión proximal de fusión con el uso del MISDEF. Conclusiones: Hay una tendencia en aumentar las indicaciones de osteotomía y disminuir la opción por tratamiento conservador en la toma de decisión con MISDEF. El uso del algoritmo no mostró impacto expresivo en la decisión terapéutica en casos graves de deformidad en adultos. Nivel de evidencia II; Análisis radiográfico prospectivo comparativo.

Descriptores: Adulto; Escoliosis; Columna Vertebral; Tratamiento Conservador; Osteotomía.

\section{INTRODUCTION}

Adult degenerative spinal deformity (ADSD) encompasses a wide variety of conditions that result in abnormal spinal alignment leading to pain, disability, neurological changes, and loss of quality of life. ${ }^{1}$ Degenerative scoliosis manifests on average around the seventh decade of life, most often in the lumbar spine, usually with the apex at L3 associated with a fractional curve between L4-S1. Its prevalence is inversely proportional to its magnitude and it may progress from $1^{\circ}$ to $6^{\circ}$ per year. ${ }^{1}$ The prevalence of ADSD in North America increased by $157 \%$ between 1999 and 2009, believed to be a result of the continued aging of the population, the increase in life expectancy, changes in the demographic profile, and also the spine surgeon's increasing understanding and knowledge of this condition. ${ }^{2}$ Individuals with ADSD present back pain resulting from symptomatic disc degeneration, facet joint arthropathy, segmental instability, or even as a consequence of the postural imbalance itself, which requires compensatory mechanisms in order to maintain the trunk in balance. Radiculopathy or claudication may also be forms of ADSD presentation, as a result of canal, recess, or foraminal stenosis arising from facet joint or ligamentum flavum hypertrophy, rotatory subluxation leading to narrowing of the foramen, or reduction of the interpedicular distance in the concavity of the curve., ${ }^{1,3}$

In the absence of progressive neurological deficit, instability, or progressive deformity, conservative treatment with physical therapy through exercises in combination with medications is the first choice for treatment. ${ }^{4,5}$ In search of a better quality of life and a more active life style, the elderly tend to turn increasingly to surgical alternatives for ADSD. The surgical alternatives range from foraminal decompression to long arthrodesis extending to the thoracic spine combined with different types of osteotomies.

Surgical management of cases of adult degenerative deformity involves the recognition of numerous conditions, such scoliosis, kyphosis, and spondylolisthesis. Historically, treatment was focused on the correction and prevention of scoliotic progression. However, recent studies have shown the impact of sagittal alignment on the generation of pain and functional deficit in these patients. ${ }^{6}$ Consequently, emphasis has been placed on restoring physiological sagittal parameters (lumbar lordosis, segmental lordosis, thoracic kyphosis, sagittal vertical axis) and reestablishing the proper spinopelvic relationships for each case.

Surgical correction of adult deformity is traditionally accomplished using open surgical approaches. Open surgery is associated with significant rates of complications such as blood loss, infection of the surgical wound, and pulmonary embolism. ${ }^{6}$

Aimed at reducing surgical morbidity and complications associated with conventional procedures, minimally invasive approaches have gained popularity in the treatment of cases of adult deformity. However, not every patient is a candidate for minimally invasive surgery. The surgical goals must be defined on a case by case basis, whether they be decompression of neural elements, establishment or maintenance of sagittal and coronal alignment, or achieving solid arthrodesis. Thus, the MISDEF algorithm was developed to assist spinal surgeons to select a treatment option appropriate for the needs of each patient. ${ }^{7}$

The objective of this study is to compare the impact of the MISDEF algorithm on the therapeutic decision in cases of adult spinal deformity.

\section{METHODS}

Forty symptomatic cases of adult degenerative deformity treated surgically by the authors were selected from a database built with patient consent. This study is part of a line of research approved by the Institutional Review Board as number 089852. The sample consisted of patients with coronal or sagittal plane deformity associated with degenerative spinal pathologies such as lumbar stenosis, symptomatic degenerative disc disease, and degenerative spondylolisthesis. Those who were younger than 45 years of age, had tumor pathologies, fractures, infection, or osteometabolic pathologies were excluded from the study. All cases included in the study provided data such as age, sex, symptomatology, panoramic radiographs with discriminated radiographic parameters ( $\mathrm{LL}$ - lumbar lordosis L1-S1, LS - segmental lordosis L4-S1, TK - thoracic kyphosis, PI - pelvic incidence, PT - pelvic tilt, SS - sacral slope, $\mathrm{PI}$-LL - difference between pelvic incidence and lumbar lordosis, CC - coronal curve, and SVA - sagittal vertical axis), and magnetic resonance images. The cases were organized and made available for evaluation by 20 surgeons from different Latin American centers, who had to choose between 6 treatment options (conservative management, isolated decompression, decompression with short fusion, decompression with fusion and interbody device, osteotomy with fusion, and osteotomy with extension of the fusion to the thoracic spine) on a case-by-case basis in two phases. In the first phase, the participating surgeons had to answer questionnaires without using the MISDEF algorithm. After 30 days, the 40 cases were randomly ordered and resent to the surgeons for them to choose a treatment alternative using the MISDEF algorithm.

The cases were organized according to preestablished radiographic parameters (pelvic inclination $<30^{\circ}$ or $\geq 30^{\circ}$, lumbar mismatch $<10^{\circ}$ or $\geq 10^{\circ}$, sagittal vertical axis $<6 \mathrm{~cm}$ or between 6 and $10 \mathrm{~cm}$ or $\geq 10 \mathrm{~cm}$, coronal curve $<20^{\circ}$ or $\geq 20^{\circ}$, thoracic kyphosis $<60^{\circ}$ or $\geq 60^{\circ}$, and the presence or absence of laterolisthesis) so they could be divided into groups. Among the 40 cases of adult deformity included in this study, $30(75 \%)$ had an SVA $<6 \mathrm{~cm}$ and $10(25 \%)$ had an SVA $\geq 6 \mathrm{~cm}$, in 7 of which the SVA was between 6 and $10 \mathrm{~cm}$ and in 3 of which was $\geqq 10 \mathrm{~cm}$. Regarding lumbopelvic mismatch (PI-LL), 12 (30\%) of the patients had PI-LL $<10^{\circ}, 21$ (52.5\%) PI-LL from $10^{\circ}$ to $30^{\circ}$, and $7(14 \%)$ had $\mathrm{PI}-\mathrm{LL} \geq 30^{\circ}$. As for pelvic tilt (PT), $24(60 \%)$ patients had $\mathrm{PT}<25^{\circ}$ and $16(40 \%) \mathrm{PT} \geq 25^{\circ}$. In the lateral radiographic evaluation of these patients, we also measured thoracic kyphosis (TK). Thirty-seven (92.5\%) presented $\mathrm{TK}<60^{\circ}$ and only 3 patients $(7.5 \%)$ presented $\mathrm{TK} \geq 60^{\circ}$. In the anteroposterior radiographic evaluation, the coronal lumbar curve (CC) and the presence of laterolisthesis were assessed. In relation to the coronal curve, 20 (50\%) patients has a $\mathrm{CC}<20^{\circ}$ and the other 20 patients, a CC $\geq 20^{\circ}$. Lumbar laterolisthesis was observed in 34 (85\%) cases. (Table 1)

The comparison among the groups was conducted with the goal of defining the impact of using the MISDEF algorithm in the therapeutic decisions of the spinal surgeons, and, through analysis of the radiographic parameters measured, to establish the relevance of using the MISDEF algorithm according to the needs of each case.

The results of the quantitative variables were described as mean, standard deviation, median, and minimum and maximum values. 
Categorical variables were described as frequencies and percentages. For the comparison of radiographic parameters in relation to the therapeutic decision made by the surgeons, the Wilcoxon non-parametric test was used. A value of $p<0.05$ indicated statistical significance. The data were analyzed using Stata/SE v.14.1 software (StataCorpLP, USA).

Table 1. Cases divided by the radiographic parameters evaluated in the study.

\begin{tabular}{|c|c|c|c|}
\hline Variable & Classification & $\mathbf{n}$ & $\%$ \\
\hline SVA & $<6$ & 30 & 75 \\
\hline & $6-10$ & 7 & 17.5 \\
\hline SVA (grouped) & $>10$ & 3 & 7.5 \\
\hline & $<6$ & 30 & 75 \\
\hline PI-LL & $\geq 6$ & 10 & 25 \\
\hline & $<10$ & 12 & 30 \\
\hline & $10-30$ & 21 & 52.5 \\
\hline PI-LL (grouped) & $>30$ & 7 & 17.5 \\
\hline & $\geq 10$ & 12 & 30 \\
\hline PT & $<25$ & 28 & 70 \\
\hline & $\geq 25$ & 24 & 60 \\
\hline TK & $<60$ & 16 & 40 \\
\hline & $\geq 60$ & 37 & 92.5 \\
\hline Latero & Yes & 3 & 7.5 \\
\hline & No & 6 & 85 \\
\hline CC & $<20$ & 20 & 15 \\
\hline & $\geq 20$ & 20 & 50 \\
\hline
\end{tabular}

SVA (sagittal vertical axis), PI-LL (pelvic incidence-lumbar lordosis), PT (pelvic tilt), TK (thoracic kyphosis), latero (laterolisthesis) and CC (lumbar coronal curve).

\section{RESULTS}

For decompression, decompression and short fusion, decompression and fusion with interbody device, and osteotomy with extension of the fusion to the thoracic spine no significant differences were encountered in relation to the number of surgeons who opted for these conducts when their decisions made with and without MISDEF were compared. For osteotomy, we observed a tendency towards an increase in the number of surgeons who chose this conduct when the decision was made with the MISDEF $(p=0.073)$. Regarding conservative treatment, there was a significant difference between the number of surgeons who chose it without MISDEF and those who made the decision with MISDEF $(p<0.001)$. We observed that the number of surgeons who indicated this treatment decreased rapidly when the decision was made with MISDEF. (Table 2)

In cases with SVA $<6 \mathrm{~cm}$, the treatment option most often selected by the surgeons was decompression and fusion with interbody device, both without and with use of the MISDEF algorithm, in $28 \%$ and $27 \%$ of cases, respectively. (Figure 1 ) In the cases in which the patients presented $S V A \geq 6 \mathrm{~cm}$, the therapeutic method most often indicated by the surgeons was osteotomy with extension to the thoracic spine in $37 \%$ of cases. Using the MISDEF algorithm, there was a tendency to treat these patients with decompression and fusion with interbody device or with osteotomy, both in $28 \%$ of cases. (Figure 2) In the cases with SVA $<6 \mathrm{~cm}$, we observed increased indications of osteotomy $(p=0.064)$ and proximal extension of the fusion $(p=0.025)$ and a decrease in the conservative treatment option $(p<0.001)$ among the decisions made with MISDEF. In the cases with SVA $\geq 6 \mathrm{~cm}$, using the MISDEF algorithm did not significantly influence the surgeons' decisions. (Table 3 )

In the cases with PI-LL $<10^{\circ}$, the most recommended option without the use of the algorithm was decompression and fusion with interbody device, in $33 \%$ of the cases. With MISDEF, the most indicated therapeutic method was isolated decompression, in $29 \%$ of the cases. (Figure 3) In the cases in which the patients presented $\mathrm{PI}-\mathrm{LL} \geq 10^{\circ}$, most of the surgeons opted for decompression and fusion with interbody device (25\% of the cases) without the use of the
Table 2. Descriptive statistics and comparison between the number of surgeons who chose the conduct with MISDEF and without MISDEF. For osteotomy, a tendency for the number of surgeons who chose this conduct to increase when the decision was made with MISDEF ( $p=0.073$ ) was observed. The number of surgeons who opted for conservative treatment decreased significantly when the decision was made with MISDEF $(p<0.001)$

\begin{tabular}{|c|c|c|c|c|c|}
\hline Conduct option & MISDEF & $\begin{array}{l}\text { Number of } \\
\text { evaluations }\end{array}$ & \begin{tabular}{|c|}
$\begin{array}{c}\text { Total } \\
\text { evaluations }\end{array}$ \\
\end{tabular} & $\begin{array}{c}\text { Percentage } \\
(\%)\end{array}$ & ${ }^{*} p$ \\
\hline \multirow[t]{2}{*}{ Decompression } & $\begin{array}{c}\text { With } \\
\text { MISDEF }\end{array}$ & 800 & & $19 \%$ & \\
\hline & $\begin{array}{l}\text { Without } \\
\text { MISDEF }\end{array}$ & 800 & 1600 & $17 \%$ & 0.528 \\
\hline \multirow[t]{2}{*}{$\begin{array}{c}\text { Decompression }+ \\
\text { short fusion }\end{array}$} & $\begin{array}{l}\text { With } \\
\text { MISDEF }\end{array}$ & 800 & & $11 \%$ & \\
\hline & $\begin{array}{l}\text { Without } \\
\text { MISDEF }\end{array}$ & 800 & 1600 & $15 \%$ & 0.637 \\
\hline \multirow[t]{2}{*}{$\begin{array}{c}\text { Decompression + } \\
\text { interbody device }\end{array}$} & $\begin{array}{c}\text { With } \\
\text { MISDEF }\end{array}$ & 800 & & $28 \%$ & \\
\hline & $\begin{array}{l}\text { Without } \\
\text { MISDEF }\end{array}$ & 800 & 1600 & $27 \%$ & 0.748 \\
\hline \multirow[t]{2}{*}{ Osteotomy } & $\begin{array}{c}\text { With } \\
\text { MISDEF }\end{array}$ & 800 & & $15 \%$ & \\
\hline & $\begin{array}{l}\text { Without } \\
\text { MISDEF }\end{array}$ & 800 & 1600 & $22 \%$ & 0.073 \\
\hline \multirow{2}{*}{$\begin{array}{l}\text { Osteotomy with } \\
\text { extension of the } \\
\text { fusion to the } \\
\text { thoracic spine }\end{array}$} & $\begin{array}{l}\text { With } \\
\text { MISDEF }\end{array}$ & 800 & & $13 \%$ & \\
\hline & $\begin{array}{l}\text { Without } \\
\text { MISDEF }\end{array}$ & 800 & 1600 & $17 \%$ & 0.264 \\
\hline \multirow[t]{2}{*}{ Conservative } & $\begin{array}{c}\text { With } \\
\text { MISDEF }\end{array}$ & 800 & & $14 \%$ & \\
\hline & $\begin{array}{l}\text { Without } \\
\text { MISDEF }\end{array}$ & 800 & 1600 & $3 \%$ & $<0.001$ \\
\hline
\end{tabular}

MISDEF (minimally invasive spine deformity algorithm). *Wilcoxon non-parametric test, $p<0.05$

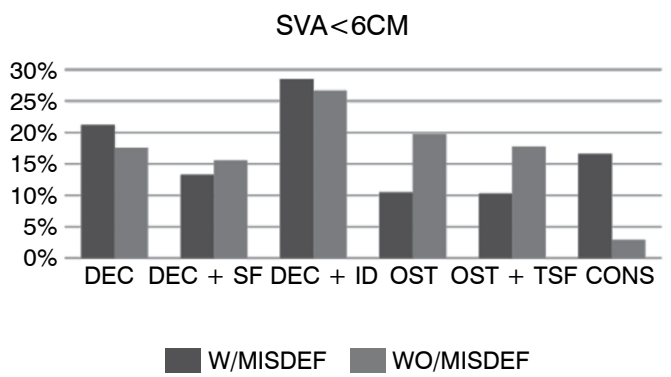

Figure 1. Conducts without and with MISDEF in the cases with $S V A<6 \mathrm{~cm}$ The most indicated option both with and without use of MISDEF was decompression and fusion with interbody device (28\% and $27 \%$, respectively). SVA (sagittal vertical axis), MISDEF (minimally invasive spine deformity algorithm). Isolated decompression (DEC), decompression and short fusion (DEC + $\mathrm{SF})$, decompression and fusion with interbody device (DEC + ID), osteotomy (OST), osteotomy with extension of the fusion to the thoracic spine (OST + TSF), conservative treatment (CONS).

MISDEF algorithm. With the algorithm, the most indicated option was decompression with interbody device, in $29 \%$ of the cases, followed by osteotomy in $27 \%$ of the cases. (Figure 4) In the cases with PI$-\mathrm{LL}<10^{\circ}$, we observed an increase in the indications of osteotomy with extension of the fusion to the thoracic spine $(p=0.010)$ and a decrease in the conservative treatment option $(p=0.008)$ in the decisions made with MISDEF. In the cases with PI-LL $\geq 10^{\circ}$, using the MISDEF algorithm did not significantly influence the decisions of the surgeons. (Table 4)

In the cases where the patients had $\mathrm{PT}<25^{\circ}$, the surgeons mainly opted for treatment with decompression and fusion with interbody device whether or not they used the MISDEF algorithm, in 31\% and $30 \%$ 


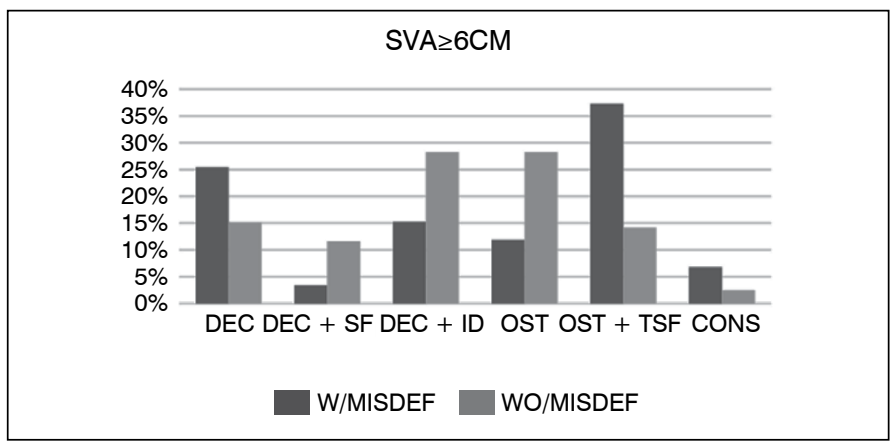

Figure 2. Conducts without and with MISDEF in the cases with $S V A \geq 6 \mathrm{~cm}$. The most indicated option without the algorithm was osteotomy with extension to the thoracic spine (37\%). With MISDEF, there was a tendency to treat with decompression and fusion with interbody device or osteotomy (both in $28 \%$ of the cases). SVA (sagittal vertical axis), MISDEF (minimally invasive spine deformity algorithm). Isolated decompression (DEC), decompression and short fusion (DEC $+\mathrm{SF})$, decompression and fusion with interbody device $(\mathrm{DEC}+\mathrm{ID})$, osteotomy (OST), osteotomy with extension of the fusion to the thoracic spine (OST + TSF), conservative treatment (CONS).

Table 3. Comparison between the conducts with and without MISDEF in the cases with $S V A<6 \mathrm{~cm}$ and $S V A \geq 6 \mathrm{~cm}$. In the cases with $S V A<6 \mathrm{~cm}$, a tendency to increase the indication of osteotomy with proximal extension $(p=0.025)$ and to decrease the conservative treatment option $(p<0.001)$ was observed in the decision made with MISDEF. In the cases with $S V A \geq 6 \mathrm{~cm}$, use of the algorithm did not significantly influence the decisions of the surgeons.

\begin{tabular}{c|c|c|c|c|c|c|c}
\hline & & \multicolumn{3}{|c|}{ SVA $<\mathbf{6}$} & \multicolumn{3}{|c}{ SVA $\geq \mathbf{6}$} \\
\hline Conduct & MISDEF & $\mathbf{N}$ & $\mathbf{( \% )}$ & ${ }^{*} \mathbf{p}$ & $\mathbf{N}$ & $\mathbf{( \% )}$ & ${ }^{*} \mathbf{p}$ \\
\hline DEC & With & 30 & $18 \%$ & & 10 & $3 \%$ & \\
\hline & Without & 30 & $21 \%$ & 0.326 & 10 & $25 \%$ & 0.415 \\
\hline DEC + SF & With & 30 & $16 \%$ & & 10 & $3 \%$ & \\
\hline & Without & 30 & $13 \%$ & 0.885 & 10 & $3 \%$ & 0.11 \\
\hline DEC + ID & With & 30 & $27 \%$ & & 10 & $32 \%$ & \\
\hline & Without & 30 & $28 \%$ & 0.517 & 10 & $15 \%$ & 0.441 \\
\hline OST & With & 30 & $20 \%$ & & 10 & $37 \%$ & \\
\hline & Without & 30 & $10 \%$ & 0.064 & 10 & $12 \%$ & 0.722 \\
\hline OST + TSF & With & 30 & $18 \%$ & & 10 & $25 \%$ & \\
\hline & Without & 30 & $10 \%$ & 0.025 & 10 & $37 \%$ & 0.142 \\
\hline CONS & With & 30 & $3 \%$ & & 10 & $0 \%$ & \\
\hline & Without & 30 & $17 \%$ & $<0.001$ & 10 & $7 \%$ & 0.208 \\
\hline
\end{tabular}

SVA (sagittal vertical axis), MISDEF (minimally invasive spine deformity algorithm). *Wilcoxon non-parametric test $p<0.05$

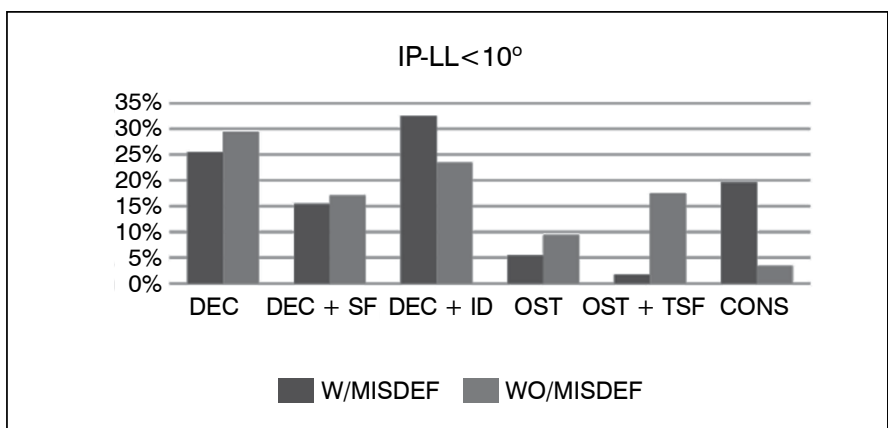

Figure 3. Conducts without and with MISDEF in the cases with $\mathrm{PI}-\mathrm{LL}<10^{\circ}$. The most often proposed option without the use of the algorithm was decompression and fusion with interbody device (33\%). With MISDEF isolated decompression (29\%) was the most indicated. PI-LL (pelvic incidence lumbar lordosis), MISDEF (minimally invasive spine deformity algorithm). Isolated decompression (DEC), decompression and short fusion (DEC + $\mathrm{SF})$, decompression and fusion with interbody device (DEC + ID), osteotomy (OST), osteotomy with extension of the fusion to the thoracic spine (OST + TSF), conservative treatment (CONS) of the cases, respectively. (Figure 5) In cases with PT $\geq 25^{\circ}$, the therapeutic methods most indicated by the participating surgeons when not using the MISDEF algorithm were decompression and fusion with interbody device and osteotomy with fusion extended to the thoracic spine, both in $23 \%$ of cases. Using the MISDEF algorithm, osteotomy was the most recommended option, in $31 \%$ of cases. (Figure 6 ) We observed a tendency of increasing indications of osteotomy with proximal extension of fusion $(\mathrm{p}=0.036)$ in patients with $\mathrm{PT}<25^{\circ}$ when the therapeutic decision was made without the algorithm. We also noted that there was a decrease in the conservative treatment option in the cases analyzed using MISDEF, both in the patients with $\mathrm{PT}<25^{\circ}$ $(p<0.001)$ and the patients with $P T \geq 25^{\circ}(p=0.050)$. (Table 5)

In cases that presented $\mathrm{TK}<60^{\circ}$, the option most indicated by the surgeons was decompression and fusion with interbody device both with and without the use of the MISDEF algorithm (25\% and $29 \%$ of the cases, respectively). (Figure 7) In cases with $\mathrm{TK} \geq 60^{\circ}$, the most indicated surgical method without the algorithm was osteotomy and fusion with extension to the thoracic spine $30 \%$ of the cases). Using the MISDEF algorithm, the surgeons opted mainly for decompression and fusion with interbody device, in $47 \%$ of the cases. (Figure 8) We observed that using the MISDEF algorithm significantly reduced $(p<0.001)$ the conservative treatment option in cases with $\mathrm{KT}<60^{\circ}$. (Table 6)

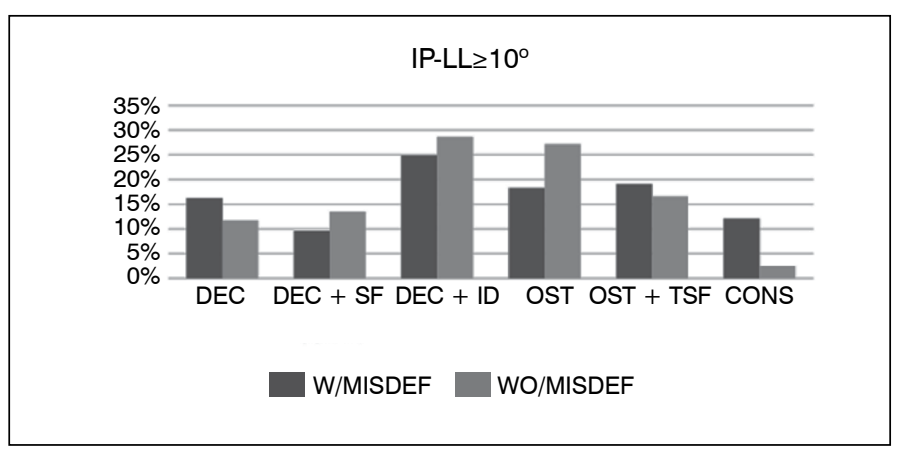

Figure 4. Conducts without and with MISDEF in the cases with $\mathrm{PI}-\mathrm{LL} \geq 10^{\circ}$ The surgeons mainly opted for decompression and fusion with interbody device without and with MISDEF (29\% and 27\%, respectively). PI-LL (pelvic incidence - lumbar lordosis), MISDEF (minimally invasive spine deformity algorithm). Isolated decompression (DEC), decompression and short fusion $(\mathrm{DEC}+\mathrm{SF})$, decompression and fusion with interbody device (DEC + ID), osteotomy (OST), osteotomy with extension of the fusion to the thoracic spine (OST + TSF), conservative treatment (CONS).

Table 4. Comparison between the conducts with and without MISDEF in the cases with $\mathrm{PI}-\mathrm{LL}<10^{\circ}$ and $\mathrm{PI}-\mathrm{LL} \geq 10^{\circ}$. In the cases with $\mathrm{PI}-\mathrm{LL}<10^{\circ}$, we observed an increase in indications of osteotomy with extension of fusion to the thoracic spine $(p=0.010)$ and a decrease in conservative treatment $(p=0.008)$ in the decisions made using MISDEF. Use of the MISDEF algorithm did not significantly influence the decisions of the surgeons in cases with PI-LL $\geq 10^{\circ}$.

\begin{tabular}{c|c|c|c|c|c|c|c}
\hline & & \multicolumn{3}{|c|}{ PI-LL $<\mathbf{1 0}$} & \multicolumn{3}{|c}{ PI-LL $\geq \mathbf{1 0}$} \\
\hline Conduct & MISDEF & $\mathbf{N}$ & $\mathbf{( \% )}$ & ${ }^{*} \mathbf{p}$ & $\mathbf{N}$ & $\mathbf{( \% )}$ & ${ }^{*} \mathbf{p}$ \\
\hline DEC & With & 12 & $29 \%$ & & 28 & $11 \%$ & \\
\hline & Without & 12 & $25 \%$ & 0.689 & 28 & $19 \%$ & 0.297 \\
\hline DEC + SF & With & 12 & $17 \%$ & & 28 & $14 \%$ & \\
\hline & Without & 12 & $15 \%$ & 0.894 & 28 & $10 \%$ & 0.638 \\
\hline DEC + ID & With & 12 & $23 \%$ & & 28 & $34 \%$ & \\
\hline & Without & 12 & $33 \%$ & 0.117 & 28 & $26 \%$ & 0.581 \\
\hline OST & With & 12 & $9 \%$ & & 28 & $25 \%$ & \\
\hline & Without & 12 & $5 \%$ & 0.314 & 28 & $15 \%$ & 0.133 \\
\hline OST + TSF & With & 12 & $17 \%$ & & 28 & $13 \%$ & \\
\hline & Without & 12 & $2 \%$ & 0.01 & 28 & $15 \%$ & 0.846 \\
\hline CONS & With & 12 & $3 \%$ & & 28 & $3 \%$ & \\
\hline & Without & 12 & $20 \%$ & 0.008 & 28 & $14 \%$ & 0.002 \\
\hline
\end{tabular}

PI-LL (pelvic incidence - lumbar lordosis), MISDEF (minimally invasive spine deformity algorithm) *Wilcoxon non-parametric test, $p<0.05$ 


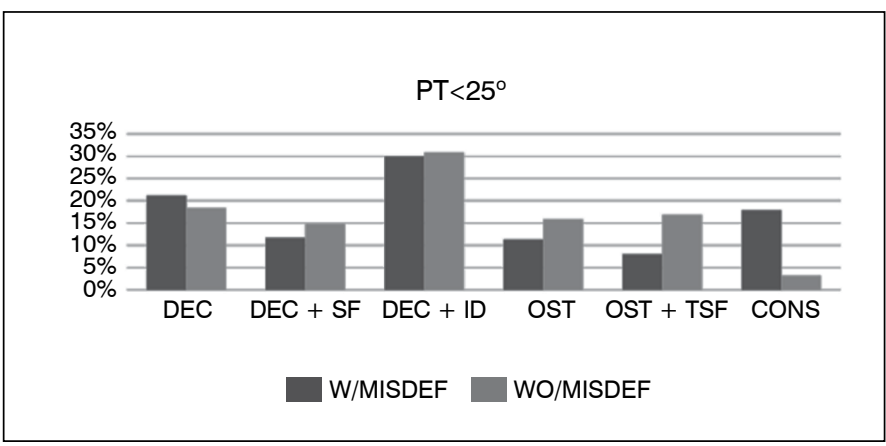

Figure 5. Conducts without and with MISDEF in the cases with $\mathrm{PT}<25^{\circ}$. The surgeons opted mainly for treatment with decompression and fusion with interbody device without and with MISDEF in 31\% and 30\% of cases, respectively. PT (pelvic tilt), MISDEF (minimally invasive spine deformity algorithm). Isolated decompression (DEC), decompression and short fusion (DEC + SF), decompression and fusion with interbody device (DEC + ID), osteotomy (OST), osteotomy with extension of the fusion to the thoracic spine (OST + TSF), conservative treatment (CONS)

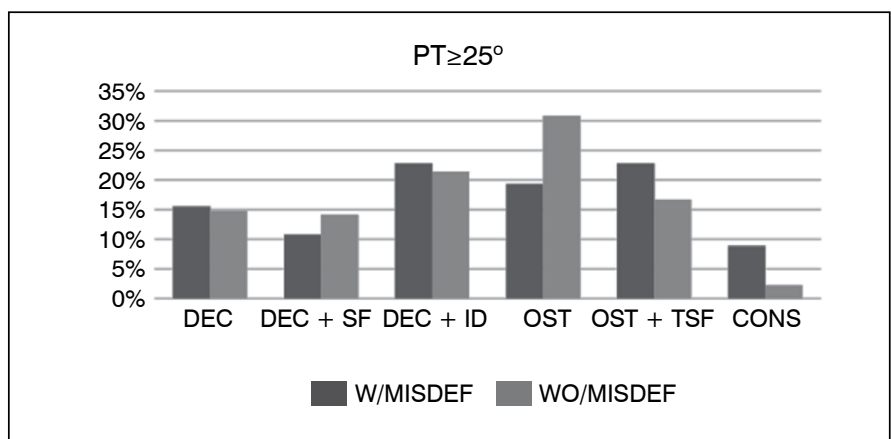

Figure 6. Conducts without and with MISDEF in the cases with $\mathrm{PT} \geq 25^{\circ}$. The methods most indicated by the surgeons without use of the algorithm were decompression and fusion with interbody device and osteotomy with extension of the fusion to the thoracic spine, both with $23 \%$ of cases. With MISDEF, the most indicated option was osteotomy (31\%). PT (pelvic tilt), MISDEF (minimally invasive spine deformity algorithm). Isolated decompression (DEC), decompression and short fusion (DEC + SF), decompression and fusion with interbody device (DEC + ID), osteotomy (OST), osteotomy with extension of the fusion to the thoracic spine (OST + TSF), conservative treatment (CONS).

Table 5. Comparison between the conducts with and without MISDEF in the cases with $\mathrm{PT}<25^{\circ}$ and $\mathrm{PT} \geq 25^{\circ}$. In the cases with $\mathrm{PT}<25^{\circ}$, a tendency to increase the indications of osteotomy with proximal extension of the fusion was observed $(p=0.036)$ without the use of MISDEF. There was a significant reduction in the conservative treatment option in the cases conducted with MISDEF. In the cases with $P T \geq 25^{\circ}$, there was a decrease in the conservative treatment option in the cases that used MISDEF

\begin{tabular}{c|c|c|c|c|c|c|c}
\hline & & \multicolumn{3}{|c|}{ PT $\geq \mathbf{2 5}$} & \multicolumn{3}{|c}{ PT $\geq \mathbf{2 5 0}$} \\
\hline Conduct & MISDEF & $\mathbf{N}$ & $\mathbf{( \% )}$ & ${ }^{*} \mathbf{p}$ & $\mathbf{N}$ & $\mathbf{( \% )}$ & ${ }^{*} \mathbf{p}$ \\
\hline DEC & With & 24 & $18 \%$ & & 16 & $15 \%$ & \\
\hline & Without & 24 & $21 \%$ & 0.532 & 16 & $16 \%$ & 0.975 \\
\hline DEC + SF & With & 24 & $15 \%$ & & 16 & $14 \%$ & \\
\hline & Without & 24 & $12 \%$ & 0.44 & 16 & $11 \%$ & 0.875 \\
\hline DEC + ID & With & 24 & $31 \%$ & & 16 & $21 \%$ & \\
\hline & Without & 24 & $30 \%$ & 0.909 & 16 & $23 \%$ & 0.691 \\
\hline OST & With & 24 & $16 \%$ & & 16 & $31 \%$ & \\
\hline & Without & 24 & $11 \%$ & 0.348 & 16 & $19 \%$ & 0.132 \\
\hline OST + TSF & With & 24 & $17 \%$ & & 16 & $17 \%$ & \\
\hline & Without & 24 & $8 \%$ & 0.036 & 16 & $23 \%$ & 0.51 \\
\hline CONS & With & 24 & $3 \%$ & & 16 & $2 \%$ & \\
\hline & Without & 24 & $18 \%$ & $<0.001$ & 16 & $9 \%$ & 0.05 \\
\hline
\end{tabular}

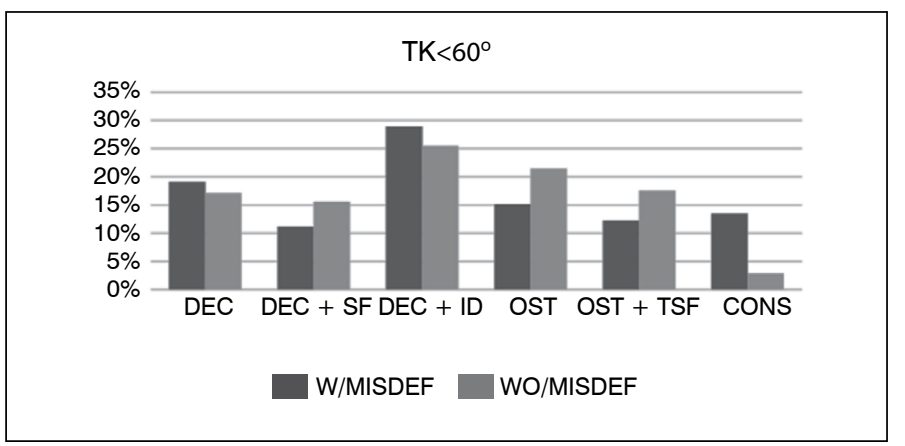

Figure 7. Conducts without and with MISDEF in the cases with $\mathrm{TK}<60^{\circ}$. The option most indicated by the surgeons, both without and with MISDEF, was decompression and fusion with interbody device (29\% and $25 \%$, respectively). TK (thoracic kyphosis), MISDEF (minimally invasive spine deformity algorithm). Isolated decompression (DEC), decompression and short fusion (DEC + $\mathrm{SF}$ ), decompression and fusion with interbody device (DEC + ID), osteotomy (OST), osteotomy with extension of the fusion to the thoracic spine (OST + TSF), conservative treatment (CONS).

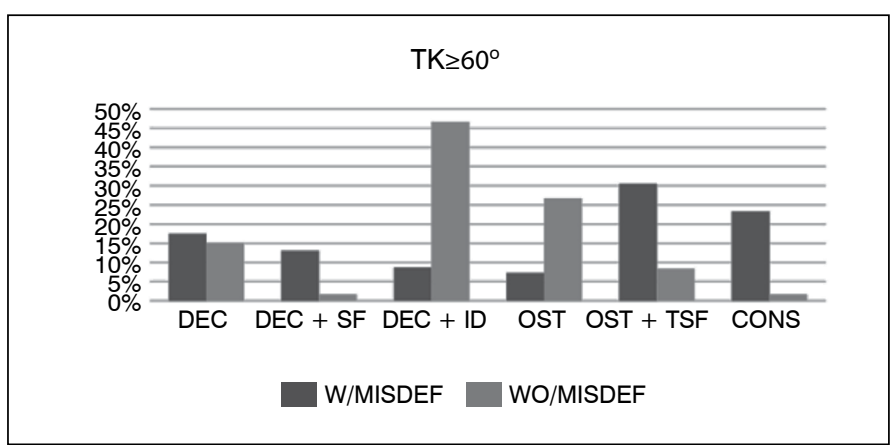

Figure 8. Conducts without and with MISDEF in the cases with $\mathrm{TK} \geq 60^{\circ}$. The most indicated surgical method without the algorithm was osteotomy and fusion with extension to the thoracic spine (30\%). With MISDEF, the surgeons opted mainly for decompression and fusion with interbody device in $47 \%$ of cases. TK (thoracic kyphosis), MISDEF (minimally invasive spine deformity algorithm). Isolated decompression (DEC), decompression and short fusion $(\mathrm{DEC}+\mathrm{SF})$, decompression and fusion with interbody device (DEC + ID), osteotomy (OST), osteotomy with extension of the fusion to the thoracic spine (OST + TSF), conservative treatment (CONS).

Table 6. Comparison between the conducts with and without MISDEF in the cases with $\mathrm{TK}<60^{\circ}$ and $\mathrm{TK} \geq 60^{\circ}$. In the cases with $\mathrm{TK}<60^{\circ}$, we observed that using the MISDEF algorithm significantly reduced $(p<0.001)$ the conservative treatment option.

\begin{tabular}{c|c|c|c|c|c|c|c}
\hline & & \multicolumn{3}{|c|}{ TK<60 } & \multicolumn{3}{c}{ TK $\geq \mathbf{6 0}$} \\
\hline Conduct & MISDEF & $\mathbf{N}$ & $\mathbf{( \% )}$ & ${ }^{*} \mathbf{p}$ & $\mathbf{N}$ & $\mathbf{( \% )}$ & ${ }^{*} \mathbf{p}$ \\
\hline DEC & With & 37 & $17 \%$ & & 3 & $15 \%$ & \\
\hline & Without & 37 & $19 \%$ & 0.62 & 3 & $17 \%$ & - \\
\hline DEC + SF & With & 37 & $16 \%$ & & 3 & $2 \%$ & \\
\hline & Without & 37 & $11 \%$ & 0.362 & 3 & $13 \%$ & - \\
\hline DEC + ID & With & 37 & $25 \%$ & & 3 & $47 \%$ & \\
\hline \multirow{2}{*}{ OST } & Without & 37 & $29 \%$ & 0.346 & 3 & $9 \%$ & - \\
\hline \multirow{2}{*}{ With } & 37 & $21 \%$ & & 3 & $27 \%$ & \\
\hline OST + TSF & Without & 37 & $15 \%$ & 0.127 & 3 & $7 \%$ & - \\
\hline \multirow{2}{*}{ WONS } & Without & 37 & $18 \%$ & & 3 & $8 \%$ & \\
\hline & With & 37 & $3 \%$ & & 3 & $2 \%$ & \\
\hline & Without & 37 & $13 \%$ & $<0.001$ & 3 & $23 \%$ & - \\
\hline
\end{tabular}

TK (thoracic kyphosis), MISDEF (minimally invasive spine deformity algorithm). *Wilcoxon nonparametric test, $p<0.05$ 
In the presence of laterolisthesis, the option most indicated by the participants was decompression and fusion with interbody device, both with and without MISDEF (in 25\% and $28 \%$ of the cases, respectively). In the absence of laterolisthesis, we observed a tendency to treat the patients with osteotomy (25\%) and fusion with extension to the thoracic spine $(26 \%)$ in cases conducted without the use of the algorithm. With the MISDEF, the surgeons opted mainly for decompression and fusion with interbody device (38\%). In the presence of laterolisthesis, the conservative treatment option decreased significantly $(p<0.001)$ with the use of MISDEF. In the cases without laterolisthesis, using the algorithm did not significantly influence the therapeutic decision. (Table 7)

In cases in which the patients had $\mathrm{CC}<20^{\circ}$, the surgeons opted mainly for decompression and fusion with interbody device when the decision was made without the algorithm (29\% of cases). With the MISDEF, the surgeons chose mainly isolated decompression and decompression and fusion with interbody device (both in $22 \%$ of cases), followed by osteotomy with proximal extension of the fusion (21\% of cases). In the patients with $\mathrm{CC} \geq 20^{\circ}$, the most indicated therapeutic method was decompression and fusion with interbody device (25\% without MISDEF and $32 \%$ with MISDEF). In the cases with $\mathrm{CC}<20^{\circ}$, the results showed an increase in the indication of osteotomy and extension of the fusion to the thoracic spine $(p=0.028)$ and a decrease in the indication of conservative treatment $(p<0.008)$ when the therapeutic decision was made through use of MISDEF. Similarly, the use of MISDEF in cases with $\mathrm{CC} \geq 20^{\circ}$ demonstrated a tendency to increase indications of osteotomy $(p=0,053)$ and decrease those of conservative treatment $(p<0.002)$. (Table 8$)$

Making the surgical decision was not significantly affected by using MISDEF in cases where the radiographic parameters suggested more severe sagittal misalignment (SVA $\geq 6 \mathrm{~cm}$ or $\mathrm{PT} \geq 25^{\circ}$ or $\mathrm{PI}-\mathrm{LL} \geq 10^{\circ}$ or $\mathrm{TK} \geq 60^{\circ}$ ). However, in the cases where patients presented SVA $<6 \mathrm{~cm}$ or $\mathrm{PT}<25^{\circ}$ or $\mathrm{PI}-\mathrm{LL}<10^{\circ}$ or $\mathrm{CC}<20^{\circ}$, the surgeons had a tendency to significantly reduce the conservative treatment indication and markedly opt for treatment with osteotomy and proximal extension of fusion to the thoracic spine when using the algorithm.

\section{DISCUSSION}

The functional and quality of life results following surgery to correct adult spinal deformity are closely correlated with restoration of spinal sagittal alignment. ${ }^{8,9}$ Schwab et al. ${ }^{10}$ evaluated postoperative functional results together with measurements of radiographic parameters in order to prepare guidelines for reconstructive spinal surgery. Based on this analysis, the goal of spinal realignment

Table 7. Comparison between the conducts with and without MISDEF in the cases with and without laterolisthesis. In the cases with laterolisthesis, there was a tendency to decrease significantly $(p<0.001)$ the conservative treatment option with the use of MISDEF. In the cases without laterolisthesis, there was no difference between the groups.

\begin{tabular}{c|c|c|c|c|c|c|c}
\hline & & \multicolumn{3}{|c|}{ With latero } & \multicolumn{3}{c}{ Without latero } \\
\hline Conduct & MISDEF & $\mathbf{N}$ & $\mathbf{( \% )}$ & ${ }^{*} \mathbf{p}$ & $\mathbf{N}$ & $\mathbf{( \% )}$ & ${ }^{*} \mathbf{p}$ \\
\hline DEC & With & 34 & $17 \%$ & & 6 & $18 \%$ & \\
\hline & Without & 34 & $20 \%$ & 0.294 & 6 & $11 \%$ & 0.294 \\
\hline DEC + SF & With & 34 & $15 \%$ & & 6 & $10 \%$ & \\
\hline & Without & 34 & $12 \%$ & 0.722 & 6 & $8 \%$ & 0.584 \\
\hline DEC + ID & With & 34 & $25 \%$ & & 6 & $38 \%$ & \\
\hline & Without & 34 & $28 \%$ & 0.284 & 6 & $22 \%$ & 0.142 \\
\hline OST & With & 34 & $21 \%$ & & 6 & $28 \%$ & \\
\hline & Without & 34 & $13 \%$ & 0.102 & 6 & $25 \%$ & 0.753 \\
\hline OST + TSF & With & 34 & $19 \%$ & & 6 & $5 \%$ & \\
\hline & Without & 34 & $12 \%$ & 0.114 & 6 & $26 \%$ & 0.465 \\
\hline CONS & With & 34 & $3 \%$ & & 6 & $2 \%$ & \\
\hline & Without & 34 & $15 \%$ & $<0.001$ & 6 & $9 \%$ & 0.109 \\
\hline
\end{tabular}

Latero (laterolisthesis), MISDEF (minimally invasive spine deformity algorithm). *Wilcoxon nonparametric test, $p<0.05$.
Table 8. Comparison between the conducts with and without MISDEF in cases with $\mathrm{CC}<20^{\circ}$ and $\mathrm{CC} \geq 20^{\circ}$. In the cases with $\mathrm{CC}<20^{\circ}$, there was a tendency to increase the osteotomy with extension of fusion to the thoracic spine option $(p=0.028)$ and decrease indications of conservative treatment $(p<0.008)$ when the therapeutic decision was conducted through use of MISDEF. In cases with $C C \geq 20^{\circ}$, there was a tendency towards increasing indications of osteotomy $(p=0.053)$ and decreasing the conservative treatment option $(p<0.002)$ with MISDEF.

\begin{tabular}{c|c|c|c|c|c|c|c}
\hline & & \multicolumn{3}{|c|}{$\mathbf{C C}<\mathbf{2 0}$} & \multicolumn{3}{|c}{ CC $\geq \mathbf{2 0}$} \\
\hline Conduct & MISDEF & $\mathbf{N}$ & $\mathbf{1 \% )}$ & ${ }^{*} \mathbf{p}$ & $\mathbf{N}$ & $\mathbf{( \% )}$ & ${ }^{*} \mathbf{p}$ \\
\hline DEC & With & 20 & $22 \%$ & & 20 & $12 \%$ & \\
\hline & Without & 20 & $22 \%$ & 0.979 & 20 & $16 \%$ & 0.365 \\
\hline DEC + SF & With & 20 & $13 \%$ & & 20 & $16 \%$ & \\
\hline & Without & 20 & $11 \%$ & 0.868 & 20 & $11 \%$ & 0.629 \\
\hline DEC + ID & With & 20 & $22 \%$ & & 20 & $32 \%$ & \\
\hline & Without & 20 & $29 \%$ & 0.211 & 20 & $25 \%$ & 0.243 \\
\hline OST & With & 20 & $20 \%$ & & 20 & $24 \%$ & \\
\hline & Without & 20 & $16 \%$ & 0.5 & 20 & $13 \%$ & 0.053 \\
\hline OST + TSF & With & 20 & $21 \%$ & & 20 & $13 \%$ & \\
\hline & Without & 20 & $9 \%$ & 0.028 & 20 & $19 \%$ & 0.492 \\
\hline CONS & With & 20 & $3 \%$ & & 20 & $3 \%$ & \\
\hline & Without & 20 & $14 \%$ & 0.008 & 20 & $15 \%$ & 0.002 \\
\hline
\end{tabular}

CC (coronal lumbar curve), MISDEF (minimally invasive spine deformity algorithm). *Wilcoxon nonparametric test, $p<0.05$.

procedures should be to achieve SVA $<50 \mathrm{~mm}$, T1S-PI (T1 slope - pelvic incidence) $<0^{\circ}$, and $\mathrm{PT}<20^{\circ}$. Additionally, the relationship between preoperative and postoperative $\mathrm{LL}$ and $\mathrm{PI}$ is fundamentally important to an understanding of spinopelvic harmony. The ideal relationship between these parameters consistent with good functional results is $\mathrm{LL}=\mathrm{PI} \pm 9^{\circ}$. Several formulas for surgical planning have been proposed focused on reestablishing postoperative sagittal alignment. Ondra et al., ${ }^{11}$ used a trigonometric method to define the angular correction necessary to achieve sagittal realignment through pedicle subtraction osteotomy. However, the contribution of the pelvis to sagittal realignment was neglected by this method. It is known that the LL necessary to restore physiological sagittal alignment is not the same in all cases but is dependent on PI. Furthermore, patients increase PT to compensate overall spinal misalignment. This compensatory increase in PT results in a greater demand for body energy, which contributes to worse functional results. For the patients with sagittal misalignment and increased PT the normalization of pelvic tilt requires greater angular correction than the technique of Ondra et al. ${ }^{11}$ prescribed. Thus, the patients with significant sagittal misalignment are at risk of subcorrection if the magnitude of the spinopelvic deformity is not recognized. If major sagittal correction is required, there are several methods to supplement PSO, including the addition of an interbody device combined with a Ponte osteotomy at the adjacent level. ${ }^{12}$ Another important factor to consider in planning surgical deformity correction is that the other spinal segments not incorporated into the fusion change their alignment. Lafage et al. ${ }^{13}$ showed that the increase in thoracic kyphosis following pedicle subtraction osteotomy surgery has a negative impact on the maintenance of the sagittal alignment of these patients. This phenomenon is more common in elderly patients with significant sagittal misalignment and high PI. However, to predict the increase in thoracic kyphosis in preoperative planning is not always possible, since patients with elevated SVA tend to reduce kyphosis through muscle contraction.

Patients with high SVA and low PT (low compensatory capacity) are a risk group for failure of spinal reconstruction surgery. Examples of this deformity pattern are patients with hip flexion contracture, patients with primary disease of the spinal extensor musculature, globally misaligned patients with secondary weakness of the extensor muscles, and patients who lean forward to compensate severe lumbar stenosis. ${ }^{14}$ Lee et al. ${ }^{15}$ divided patients with degenerative sagittal misalignment into two subgroups; those who have the ability to maintain PT while walking and those who do not have this ability and, 
consequently, walk leaning towards the front. Pelvic retroversion is used as a compensatory mechanism during ambulation to maintain alignment, which places the pelvis in a non-physiological position. The ability to maintain pelvic retroversion while walking demonstrates adequate extensor muscle tone, but with increased energetic expenditure, external hip rotation, and internal knee rotation. ${ }^{16}$

Glassman et al. ${ }^{17}$ demonstrated that spinal sagittal alignment is the most reliable radiological predictor of the clinical and functional state in patients with adult degenerative deformity. Patients with a positive sagittal vertical axis report more pain, functional deficit, and dissatisfaction with self-image. The observation that overall sagittal alignment is a significant predictor of clinical status is consistent with the experience of Emami et al., where patients with positive sagittal vertical alignment presented more pain following long fusions to the sacrum as compared to the patients with negative SVA. ${ }^{18}$ Regarding coronal deformity in these patients, it was observed in the study that coronal misalignment greater than $4 \mathrm{~cm}$ was associated with deterioration of functional scores and with pain in non-operated patients, but did not yield the same outcomes in patients with prior surgery. These data suggest that coronal correction does not appear to be as important as correction of sagittal misalignment and that, it is likely that complete correction of coronal alignment would result in functional outcomes significantly better than those from partial correction. Given the importance of achieving spinopelvic harmony after adult degenerative deformity correction surgery, preoperative evaluation of the sagittal vertical axis, pelvic tilt, pelvic incidence, lumbar lordosis, and thoracic kyphosis is part of surgical planning in these patients. ${ }^{19-21}$

During the last decades, open surgical techniques such as osteotomies and interbody fusions have been used to achieve the necessary correction of adult spinal deformity and effectively achieve adequate sagittal alignment in each case. ${ }^{22,23}$ Currently, minimally invasive techniques have been introduced into the therapeutic arsenal to reduce the comorbidities and complications associated with open surgery. However, not all cases are candidates for correction through minimally invasive techniques, which are limited in terms of achieving large angular corrections in cases of rigid deformities with severe sagittal misalignment. Recent studies have shown several preoperative predictors of suboptimal corrections of adult deformities. Common preoperative predictors of inadequate spinal correction include rigid curves with SVA $>6 \mathrm{~cm}, \mathrm{PT}>25^{\circ}, \mathrm{PI}-\mathrm{LL}>30^{\circ}$, and thoracic hyperkyphosis greater than $60^{\circ} .24-28$

The MISDEF algorithm was developed with the goal of assisting the spinal surgeon to make a therapeutic decision in cases of adult spinal deformity. MISDEF takes the preoperative radiographic parameters into account in order to help in selecting the patients who are candidates for minimally invasive surgery. Using this algorithm, the surgeon can evaluate whether the patient is a candidate for 1 or 2 levels of isolated decompression or fusion limited to a single level of spondylolisthesis. These patients usually have flexible curves with $\mathrm{PI}-\mathrm{LL}<10^{\circ}$, SVA $<6 \mathrm{~cm}, \mathrm{PT}<25^{\circ}$, minimal laterolisthesis, $\mathrm{CC}<20^{\circ}$, and the absence of thoracic hyperkyphosis. Patients with moderate spinal deformity, that is, PI-LL between $10^{\circ}$ and $30^{\circ}$, laterolisthesis $>6 \mathrm{~mm}$, or CC $>20^{\circ}$ (MISDEF class II) are candidates for minimally invasive decompression, fusion with interbody device, and fixation of the coronal curve apex with pedicle screws. However, patients with severe deformity, that is, rigid curves with SVA $>7 \mathrm{~cm}$, $\mathrm{PI}-\mathrm{LL}>30^{\circ}, \mathrm{PT}>25^{\circ}$, and thoracic hyperkyphosis greater than $60^{\circ}$ are not candidates for minimally invasive surgeries, since there is not enough scientific evidence demonstrating that MIS techniques have the potential to correct significant deformities, particularly in the sagittal plane. In contrast, open procedures including osteotomies can achieve appropriate angular corrections. ${ }^{7}$

This study showed that decision making by the participating surgeons was not significantly affected using MISDEF in cases where the radiographic parameters suggested more severe sagittal alignment $\left(\mathrm{SVA} \geq 6 \mathrm{~cm}\right.$ or $\mathrm{PT} \geq 25^{\circ}$ or $\mathrm{PI}-\mathrm{LL} \geq 10^{\circ}$ or $\left.\mathrm{TK} \geq 60^{\circ}\right)$. However, in the cases in which the patients presented SVA $<6 \mathrm{~cm}$ or $\mathrm{PT}<25^{\circ}$ or $\mathrm{PI}-\mathrm{LL}<10^{\circ}$ or $\mathrm{CC}<20^{\circ}$, the surgeons showed a tendency to significantly reduce their indications of conservative treatment and opt strongly for treatment with osteotomy and proximal extension of the fusion to the thoracic spine when assisted by the algorithm.

It is important to emphasize that the radiographic parameters should always be assessed together for a better understanding of overall spinal alignment. The treatment option should be selected according to the needs of the case and the clinical conditions of each patient individually.

Although the MISDEF algorithm does not include an indication of conservative treatment, we believed it necessary to give this option to the participating surgeons in both phases of the study, given that many cases of adult deformity occur in elderly patients with low biological reserves and who, due to multiple comorbidities, may present contraindications to highly complex invasive procedures. The tendency to decrease conservative treatment indications in making a decision with MISDEF may indicate that the algorithm truly assists surgeons to select the patients who are candidates for minimally invasive procedures.

\section{CONCLUSIONS}

There is a tendency to increase indications of osteotomy and decrease the conservative treatment option when making decisions with the MISDEF algorithm. Use of the algorithm did not show a significant impact on therapeutic decisions in serious cases of adult spinal deformity

All authors declare no potential conflict of interest related to this article.

CONTRIBUTION OF THE AUTHORS: Each author made significant individual contributions to the manuscript. GZR: preparation of the research project, data analysis, statistical analysis, writing, review. EV: preparation of the research project, data analysis, statistical analysis, writing, review. RLP: research project design, data analysis, statistical analysis, writing, review. CM, MSG,NGM, AF, CJJ, LRV, RF, GH.

\section{REFERENCES}

1. Ailon T, Smith JS, Shaffrey Cl, Lenke LG, Brodke D, Harrop JS, et al. Degenerative spinal deformity. Neurosurgery. 2015;77(4):S75-91.

2. Ames CP, Scheer JK, Lafage V, Smith JS, Bess S, Berven SH, et al. Adult Spinal Deformity: Epidemiology, Health Impact, Evaluation, and Management. Spine Deform. 2016;4(4):310-22.

3. Hawasli AH, Chang J, Yarbrough CK, Steger-May K, Lenke LG, Dorward IG. Interpedicular height as a predictor of radicular pain in adult degenerative scoliosis. Spine J. 2016;16(9):1070-8.

4. Everett CR, Patel RK. A systematic literature review of nonsurgical treatment in adult scoliosis. Spine (Phila Pa 1976). 2007:32(19 Suppl):S130-4

5. Glassman SD, Carreon LY, Shaffrey Cl, Polly DW, Ondra SL, Berven SH, et al. The costs and benefits of nonoperative management for adult scoliosis. Spine (Phila Pa 1976) 2010;35(5):578-82

6. Ames CP. Smith JS, Scheer JK, Bess S, Berderman SS, Deviren V, et al. Impact of spinopelvic alignment on decision making in deformity surgery in adults: a review. J Neurosurg Spine. 2012;16(6):547-64.

7. Mummaneni PV Shaffrey Cl, Lenke LG, Park P. Wang MY, La Marca F et al. The minimally invasive spinal deformity surgery algorithm: a reproducible rational framework for decision making in minimally invasive spinal deformity surgery. Neurosurg Focus. 2014; 36(5):E6.

8. Glassman SD, Berven S, Bridwell K. Horton W. Dimar JR. Correlation of radiographic parameters and clinical symptoms in adult scoliosis. Spine (Phila Pa 1976). 2005;30(6):682-88.

9. Hori T, Kawaguchi Y, Kimura T. How does the ossification area of the posterior lon- 
gitudinal ligament progress after cervical laminoplasty? Spine (Phila Pa 1976). 2006;31(24):2807-12.

10. Schwab F. Patel A, Ungar B, Farcy JP, Lafage V. Adult spinal deformity-postoperative standing imbalance: how much can you tolerate? An overview of key parameters in assessing alignment and planning corrective surgery. Spine (Phila Pa 1976). 2010:35(25):2224-31

11. Ondra SL, Marzouk S, Koski T, Silva F, Salehi S. Mathematical calculation of pedicle subtraction osteotomy size to allow precision correction of fixed sagittal deformity. Spine (Phila Pa 1976). 2006:31(25):973-9

12. Schwab FJ, Patel A, Shaffrey Cl, Smith JS, Farcy JP, Boachie-Adjei O, et al. Sagittal realignment failures following pedicle subtraction osteotomy surgery: are we doing enough? Clinical article. J Neurosurg Spine. 2012:16(6):539-46.

13. Lafage V, Ames C, Schwab F, Klineberg E, Akbarnia B, Smith J, et al. Changes in thoracic kyphosis negatively impact sagital alignment following lumbar pedicle subtraction osteotomy: a comprehensive radiographic analysis. Spine (Phila Pa 1976). 2012:37(3):180-7.

14. Lafage V, Schwab F, Vira S, Hart R, Burton D, Smith JS, et al. Does vertebral level of pedicle subtraction osteotomy correlate with degree of spinopelvic parameter correction? Clinical article. J Neurosurg Spine. 2011:14(2):184-91.

15. Lee CS, Lee CK, Kim YT, Hong YM, Yoo JH. Dynamic sagittal imbalance of the spine in degenerative flat back: significance of pelvic tilt in surgical treatment. Spine (Phila Pa 1976). 2001;26(18):2029-35

16. Sarwahi V, Boachie-Adjei O, Backus SI, Taira G. Characterization of gait function in patients with postsurgical sagital (flatback) deformity: a prospective study of 21 patients. Spine (Phila Pa 1976). 2002;27(21):2328-37.

17. Glassman SD, Bridwell K, Dimar JR, Horton W, Berven S, Schwab F. The impact of positive sagittal balance in adult spinal deformity. Spine (Phila Pa 1976). 2005;30(18):2024- 9.

18. Kim YJ, Bridwell KH, Lenke LG, Rhim S, Cheh G. An analysis of sagittal spinal alignment following long adult lumbar instrumentation and fusion to L5 or S1: can we predict ideal lumbar lordosis? Spine (Phila Pa 1976). 2006;31(20):2343-52.

19. Lafage V, Bharucha NJ, Schwab F, Hart RA, Burton D, Boachie-Adjei O, et al. Multicente validation of a formula predicting postoperative spinopelvic alignment. J Neurosurg Spine.
2012;16(1):15-21

20. Lafage V, Schwab F, Vira S, Patel A, Ungar B, Farcy JP. Spino- pelvic parameters following surgery can be predicted: a preliminary formula and validation of standing alignment. Spine (Phila Pa 1976). 2011;36(13):1037-45

21. Smith JS, Bess S, Shaffrey Cl, Burton DC, Hart RA, Hostin R, et al. Dynamic changes of the pelvis and spine are key to predicting postoperative sagittal alignment following pedicle subtraction osteotomy: a critical analysis of preoperative planning techniques. Spine (Phila Pa 1976). 2011;37(10):845-53.

22. Smith JS, Shaffrey Cl, Berven S, Glassman S, Hamill C, Horton W, et al. Improvement of back pain with operative and nonoperative treatment in adults with scoliosis. Neurosurgery. 2009;65(1):86-94.

23. Smith JS, Shaffrey Cl, Berven S, Glassman S, Hamill C, Horton W, et al. Operative versus nonoperative treatment of leg pain in adults with scoliosis: a retrospective review of a prospective multicenter database with two-year follow-up. Spine (Phila Pa 1976) 2009;34(16):1693-8.

24. Acosta FL, Liu J, Slimack N, Moller D, Fessler R, Koski T. Changes in coronal and sagital plane alignment following minimally invasive direct lateral interbody fusion for the treatment of degenerative lumbar disease in adults: a radiographic study. Clinical article. J Neurosurg Spine. 2011;15(1):92-6.

25. Blondel B, Schwab F, Ungar B, Smith J, Bridwell K, Glassman S, et al. Impact of magnitude and percentage of global sagital plane correction on health-related quality of life at 2-years follow-up. Neurosurgery. 2012;71(2):341-8.

26. Silva FE, Lenke LG. Adult degenerative scoliosis: evaluation and management. Neurosurg Focus. 2010 28(3):E1.

27. Tormenti MJ, Maserati MB, Bonfield CM, Okonkwo DO, Kanter AS. Complications and radiographic correction in adult scoliosis following combined transpsoas extreme lateral interbody fusion and posterior pedicle screw instrumentation. Neurosurg Focus. 2010;28(3):E7.

28. Wang MY, Mummaneni PV. Minimally invasive surgery for thoracolumbar spinal deformity: initial clinical experience with clinical and radiographic outcomes. Neurosurg Focus 2010;28(3):E9. 